\title{
O efeito das diferentes técnicas histológicas em estudos que envolvem mensurações
}

Maria Antonieta Lopes de Souza* Isabel da Silva Lauxen**

\begin{abstract}
RESUMO
O trabalho analisa as alteraçōes dimensionais decorrentes das diferentes técnicas de processamento histológico em estruturas complexas como a mandíbula, que abriga diferentes tecidos mineralizados e diferentes tecidos moles. A partir dos resultados obtidos conclui-se que, em estudos que envolvem mensuraçōes em cortes histológicos é necessário considerar que a técnica de inclusăo em parafina produz contração no material, o mesmo ocorrendo, porém em menor escala com material congelado, quando comparados com material nảo descalcificado.
\end{abstract}

\section{SUMMARY}

This research makes an analysis of the dimensional changes produced by different technical histologic procedure in a complex structure like mandible that has hard tissues and soft one.

From the results it was concluded that in studies where measurements are supposed to be performed it is necessary to take into account that paraffin embedding produces contraction as does frezing technic although in a smaller amount, when these are compared to material that has not been decalcified.

\section{DESCRITORES}

TÉCNICA HISTOLÓGICA • RATOS • ESTUDOS DE AVALIAÇĀO

\section{INTRODUÇÃO}

É sabido que o método de processar os tecidos causa alteraçōes dimensionais nos mesmos, e isto já foi quantificado em tecidos homogêneos, como por exemplo o cérebro (Brain, 1966). Mas em estruturas complexas como a mandíbula (óssea) com todos os seus componentes, este critério ainda nāo havia sido avaliado.

Para tal, usou-se a análise de várias mediçōes em um estudo histológico transversal em ratos, os quais tinham idade entre 10 e 40 dias, o que representa o período em que o desenvolvimento radicular, a erupçāo $\theta$ o estabelecimento da oclusāo dos primeiros molares ocorrem.

\section{MATERIAL E MÉTODOS}

Foram utilizados 117 ratos Wistar, os quais foram sacrificados em grupos de animais em intervalos de três dias, no período de 10 a 40 dias de vida (aos 10, $13,16,19,22,25,28,31,34,37$ e 40 dias). Após dissecadas, as mandíbulas foram separadas em séries contendo representantes de todos os grupos de idades e foram então utilizadas três diferentes técnicas histológicas.

a. Resina de Poliester: Fixação em formol tamponado a $10 \%$, inclusāo em Clear Casting Resin (sem demineralizaçāo), cortes seriados de 100 micrômetros, montagem em lâminas.

b. Parafina Histológica/Cera: Fixaçāo em formol tamponado a $10 \%$, desmineralizaçāo em EDTA a 10\%, inclusảo em parafina histológica/cera, cortes seriados de 6 micrômetros, montagem em lâminas.

c. Congelamento: Desmineralizaçāo em EDTA a $10 \%$ (a $40^{\circ} \mathrm{C}$ e sem fixaçāo prévia), trimagem das peças, congelamento instantâneo em isopentano resfriado com Nitrogênio líquido, cortes seriados de 10 micrômetros, montagem em lâminas.

As mediçōes foram feitas por mensuraçāo direta da lâmina, usando-se uma ocular quadriculada calibrada em micrômetros. Todas as medidas foram tomadas com o microscópio em magnitude constante, no "Conference Projector" Gillette and Sibert.

* Professora Adjunta Instituto de Biociências - UFRGS

** Bióloga - Téc. Laboratório de Patologia Buco-Dental - UFRGS 
Número de Espécimes por Técnica Histológica

\begin{tabular}{|c|c|c|c|c|}
\hline IDADES & $\begin{array}{c}\text { RESINA DE } \\
\text { POLIESTER }\end{array}$ & $\begin{array}{c}\text { CONGELA- } \\
\text { MENTO }\end{array}$ & $\begin{array}{c}\text { PARAFINA } \\
\text { /CERA }\end{array}$ & TOTAL \\
\hline 10 dias & 3 & 1 & 4 & 8 \\
13 dias & 4 & 6 & 3 & 13 \\
16 dias & 4 & 3 & 4 & 11 \\
19 dias & 4 & 2 & 6 & 12 \\
22 dias & 3 & 5 & 4 & 12 \\
25 dias & 3 & 6 & 5 & 14 \\
28 dias & 4 & 4 & 2 & 10 \\
31 dias & 3 & 6 & 2 & 11 \\
34 dias & 4 & 3 & 2 & 9 \\
37 dias & 4 & 4 & 2 & 10 \\
40 dias & 4 & 2 & 1 & 7 \\
\cline { 1 - 5 } & 40 & 42 & 35 & \multicolumn{2}{|c}{}
\end{tabular}

Descrição dos termos utilizados para especificar as paredes do alvéolo do molar, do canal do nervo dentário inferior e alvéolo do incisivo.

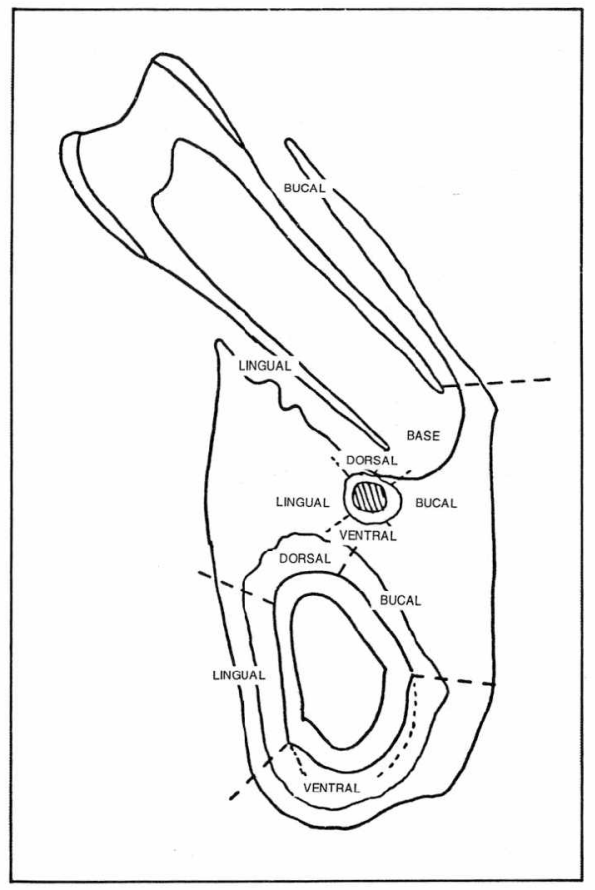

\section{RESULTADOS}

Para avaliar as alteraçōes dimensionais que podem ocorrer como consequência do processamento histológico optou-se por analisar determinados parâmetros que com mais facilidade evidenciariam distorçōes decorrentes da técnica.

Estes parâmetros foram:

1. Largura do primeiro molar inferior de rato ao nível da junçāo esmaltecemento de lingual para

\section{bucal}

Supunha-se que manter-se-ia constante, uma vez que estes tecidos duros após formados não sofrem alteraçōes dimensionais.

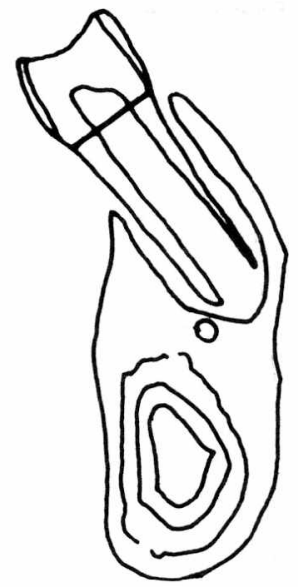

Os resultados obtidos evidenciam a manutençảo desta dimensảo em todas as faixas etárias estudadas nos ratos, mostrando porém que as técnicas produziram valores diferentes entre si.

Os valores médios obtidos em cada uma das técnicas empregadas ao longo do período estudado foram:

Resina de Poliester: 1032 micrômetros (mais ou menos) 64 micrômetros

Congelamento: 983 micrômetros (mais ou menos) 90 micrómetros
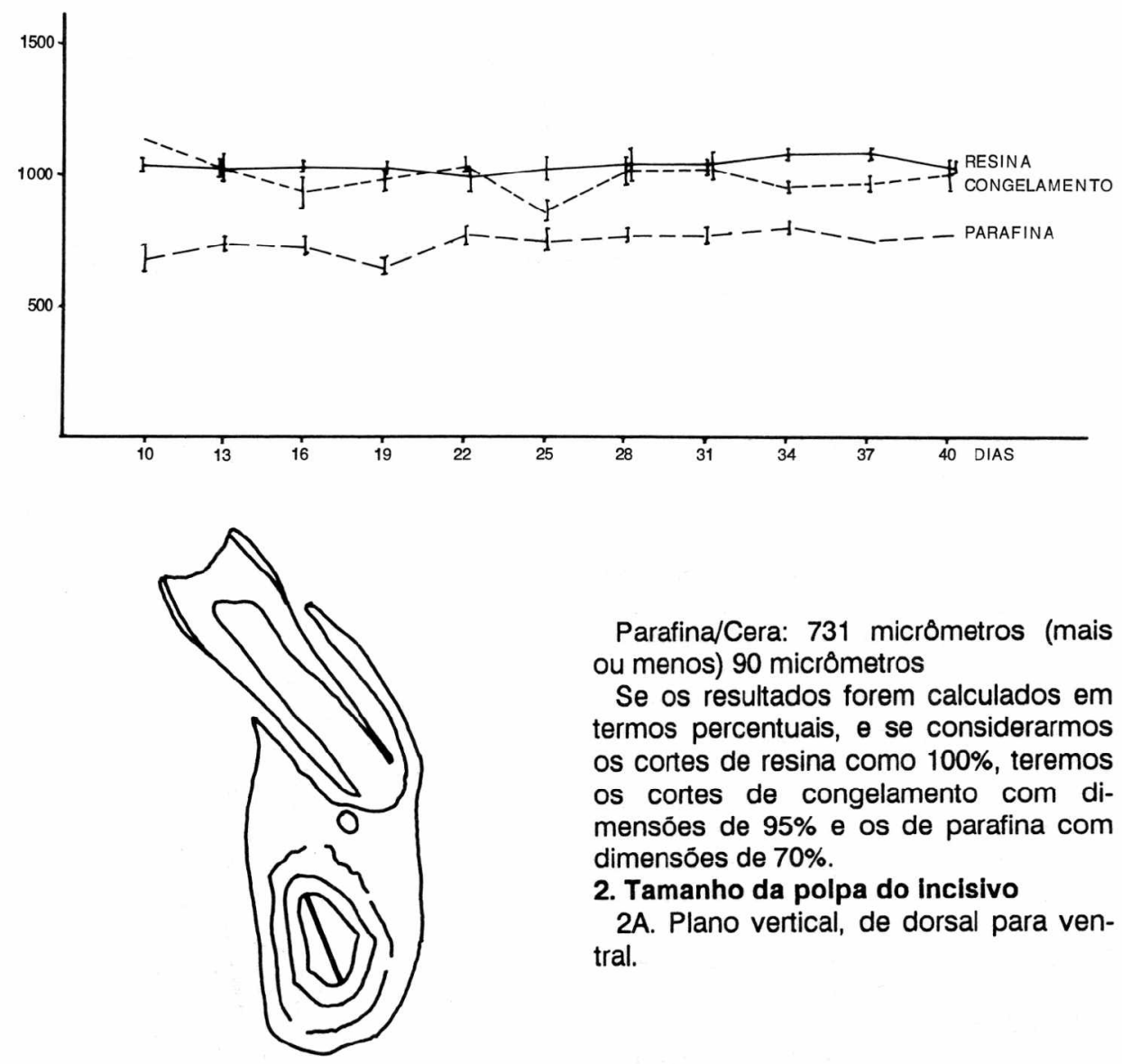

Parafina/Cera: 731 micrômetros (mais ou menos) 90 micrômetros

Se os resultados forem calculados em termos percentuais, $\theta$ se considerarmos os cortes de resina como $100 \%$, teremos os cortes de congelamento com dimensōes de $95 \%$ e os de parafina com dimensōes de $70 \%$.

2. Tamanho da polpa do incisivo

$2 \mathrm{~A}$. Plano vertical, de dorsal para ventral.

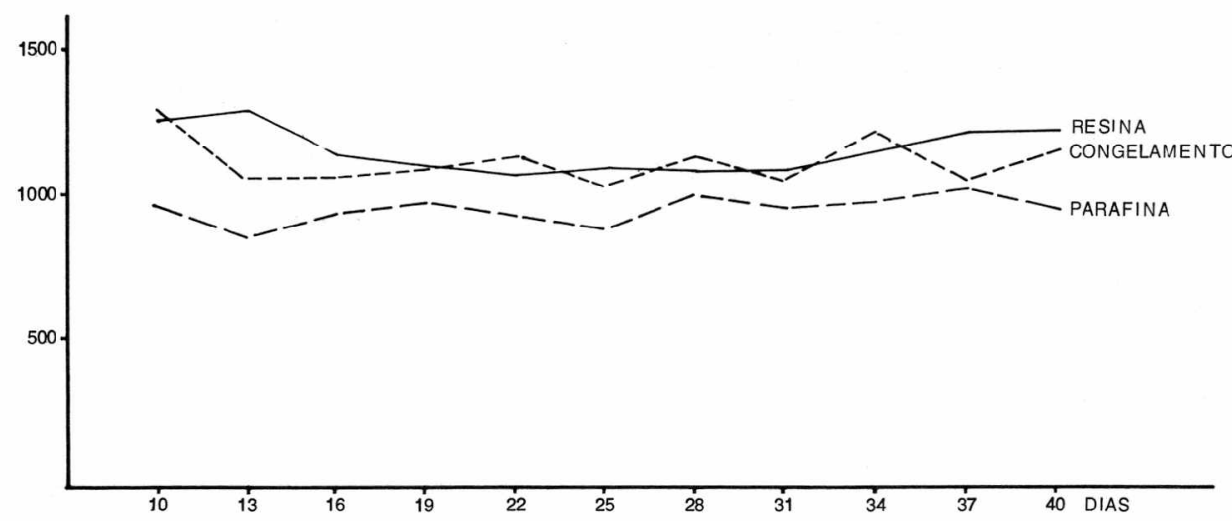


2B. Plano horizontal, de bucal para lingual

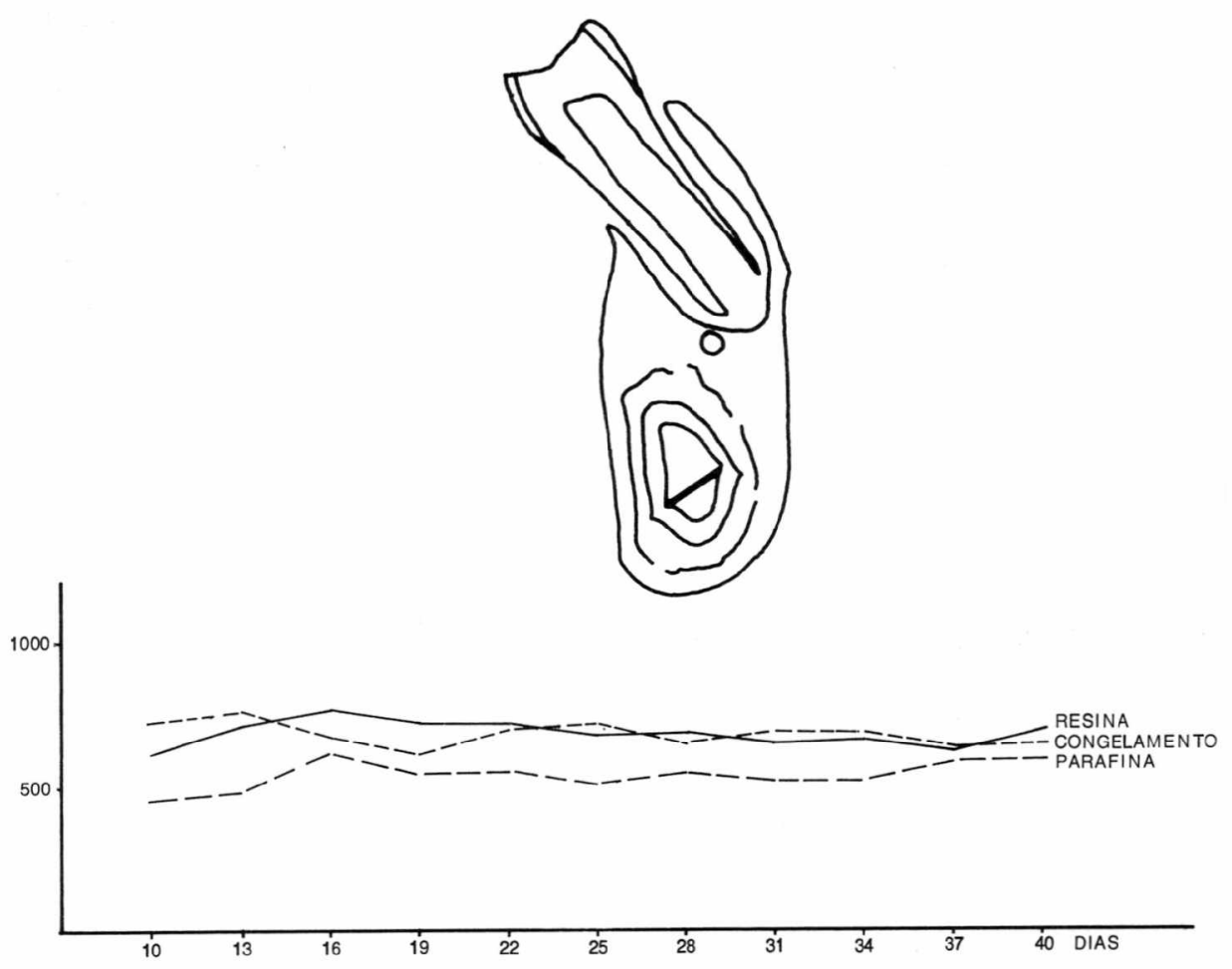

Como o crescimento da raiz dos incisivos de ratos se localiza na porção distal da mesma, optou-se pela mensuração de duas dimensōes na polpa que consistiram na avaliaçāo do maior diâmetro da polpa nos dois planos acima mencionados.

Os cortes do material incluído em resina mostraram valores muito semelhantes aos de congelamento. Os cortes de parafina apresentam os mais baixos valores, contração de cerca de $20 \%$.

\section{Distância entre o centro do incisivo \\ e o centro do canal do nervo \\ dentário inferior}

Utilizando esta dimensão pretendeu-se avaliar o efeito dos diferentes modos de processamento sobre vários tecidos que distribuem-se ao longo da distância mensurada, tais como: tecido ósseo, tecido conjuntivo do ligamento periodontal, dentina e polpa do incisivo.

Segundo Darling e Levers (1975) em humanos e De Souza (1981) em ratos, o canal do nervo dentário inferior pode ser considerado como um ponto fixo.

Os valores dos cortes de resina e congelamento sāo muito semelhantes. As mensuraçōes dos cortes de material incluído em parafina são as de menor valor. Todas as linhas seguem a mesma curva de ascensảo.

\section{CONCLUSÃO}

Utilizando mensuraçōes realizadas onde puderam ser comparadas três técnicas de preparo de material para estudos histológicos, pode-se observar que a técnica de inclusāo em parafina provoca uma redução dimensional do espécime devido provavelmente a contraçăo provocada pela temperatura na qual a parafina é utilizada.

Partindo da premissa de que o material nāo descalcificado, que é incluído na resina nảo sofre alteração dimensional (embora a inclusão em resina seja realizada sob uma pressāo negativa de -25 p.s.i.) podemos estipular o valor máximo $(100 \%)$ para as mensuraçōes dele obtidas.

Comparando entāo as mediçōes onde foram empregadas as duas técnicas restantes, observa-se que o índice de contraçāo é em torno de $20 \%$ a $30 \%$ para o material incluído em parafina, e em torno de $5 \%$ para o material que foi congelado.

De onde se conclui que ao realizar estudos que envolvam mensuraçōes deve ser tomado especial cuidado com a técnica a ser empregada, assim como devem ser levados em consideração os índices acima referidos quando se tratar de espécimes que tem tecidos duros e moles, como a mandíbula.

\section{REFERÊNCIAS BIBLIOGRÁFICAS}

1. BRAIN, E.B. The preparation of Decalcified Sections. Springfield: Illinois, 1966. Thomas, 1966.

2. BRASH, J.C. The growth of the alveolar bone and its relation to the movements of the teeth including eruption. Int. J. Orthod. v. 14. p. $196-223,283-93,398-405,487-94$ 494-504, 1928.

3. DARLING, A.I.; LEVERS, B.G.H. The pattern of eruption of some human teeth. Arch Oral Biol. 20, 89-96, 1975.

4. DE SOUZA, M.A.L. A morphometric and histological study on the development and eruption of the mandibular first molar tooth.

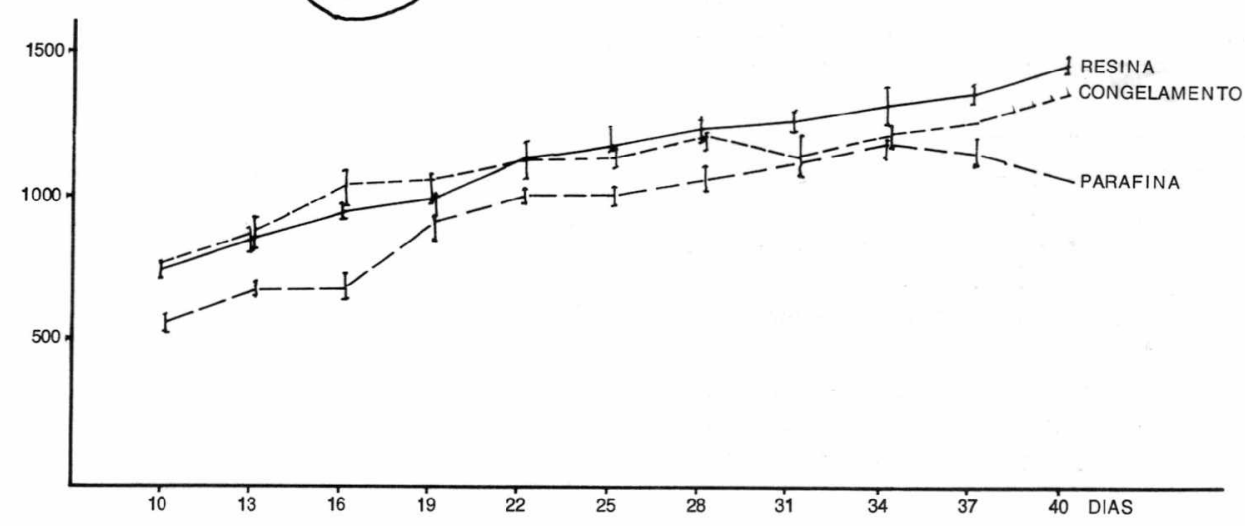


Thesis (Master of Science) University of New Castle upon tine, New Castle upon Tyne, Inglaterra, 1981.

5. GAUNT, W.A. Studies on the growth of mouse tooth germs in relation to the development of the facial region. London, 1963. Thesis. University of London, 1963.

6. HOFFMAN, M.M.; SCHOUR, I. Quantitative studies in the development of the rat molar II - Alveolar bone, cementum and eruption (from birth to 500 days). Am. J. Orthod. Oral Surg., v. 26, p. 854, 1940.

7. JOHANNESSSEN, L.B. Presence of enamel covered cusps in rat molars. Arch. Oral Biol. v. 5, p. 61-62, 1961.

8. RIESENFELD, A. Sexual dimorphism of bone robusticity in different strains of rats. Acta. Anat., v. 98, p. 206-209, 1977.

9. TOMPSETT, D.H. Anatomical Techniques. 2. ed. Edinburgh: Livingstone, 1970. 